\title{
Socialización de la salud y urbanismo en Elche a finales del siglo XIX
}

Socialization of Health and Urbanism in Elche at the End of the XIX

Century

María Rosa Gómez Martínez

Universidad de Murcia

\section{RESUMEN}

Este artículo trata de analizar la respuesta municipal que produce la epidemia de cólera de 1884 en cuanto a la deconstrucción urbanística y arquitectónica de la ciudad según criterios de salud pública e higienismo, en Elche, ciudad del Mediterráneo occidental. Esta deconstrucción se desarrolla según cuatro categorías: la distribución urbana en calidad de nueva ciudad; extinción de la ciudad rural, que se traduce en la superación de la dialéctica huertos-espacios urbanos; la necesidad de obra pública; la apertura de espacios públicos de ventilación y la concienciación de higiene pública/privada. Cuatro categorías que sintetizan los contenidos de una intervención municipal que situamos en el contexto de biopolítica del Estado a finales del siglo XIX en Europa.

PALABRAS CLAVE: salud pública, urbanismo, epidemia de cólera, socialización de la salud, biopolítica

\section{ABSTRACT}

This article tries to analyze the municipal response produced by the cholera epidemic of 1884 regarding the urban and the architectural deconstruction of the city, according to the criteria of public health and hygiene, in Elche, city of the western Mediterranean. This deconstruction is developed according to four categories: urban distribution as a new city; the extinction of the rural city, 
which translates into overcoming the urban-urban spaces dialectic; the need for public works; the opening of public ventilation spaces and public / private hygiene awareness. Four categories that synthesize the contents of a municipal intervention that we place in the context of state bipolitics at the end of the nineteenth century in Europe.

KEY WORDS: public health, urbanism, epidemic of cholera, socialization of health, biopolitics

\section{INTRODUCCIÓN}

El principal objetivo de este artículo es presentar los resultados de una investigación local sobre las transformaciones urbanísticas que una ciudad concreta, Elche, desarrolla como estrategia ante las recurrentes epidemias de cólera que padece. Este estudio pretende ofrecer un modelo de interpretación útil para el análisis de otras ciudades o espacios que participen de las dinámicas, ecológicas, económicas, sociales y/o culturales del Mediterráneo. Nuestro análisis parte de la imbricación de las características de la sociedad con las condiciones de desarrollo para la salud a través del urbanismo. De modo que salud, sociedad y urbanismo se comportan como un todo dialéctico. Las condiciones sociales que determinan el desarrollo de la salud colectiva son un bien escaso, es decir, estos factores se comportan, desde el punto de vista material -económico- como aquellos bienes que, para aumentar su disponibilidad, son necesarios sacrificar.

El concepto socialización de la salud, propio del siglo XIX, y sobre todo del higienismo y el desarrollo demográfico vinculado a la industrialización, requiere una serie de condiciones generales que suponen la intervención municipal en el desarrollo industrial, es decir, por una parte se tiende a la reubicación de los espacios fabriles -fuera del casco urbano-, por otra, se intentan controlar los efectos de las industrias en materia de residuos. Esta política sociosanitaria local choca en parte con el avance industrial desregularizado de ese primer capitalismo manufacturero, urbano, tan característico de los modelos mediterráneos.

A finales del siglo XIX, el control de la sanidad dependía directamente de la administración municipal. Las competencias y recursos eran muy limitados. En el caso de Elche, una ciudad de unos 20.000 habitantes, tanto las actitudes de las autoridades como las del conjunto de la sociedad civil cambian en el momento en que la población recibe la visita del cólera en 1884 (Monge 2018: 31-37). Esta 
circunstancia dramática produce una respuesta articulada, tanto desde la iniciativa de las citadas autoridades municipales -alcalde, concejales y médico municipal- como de otros sectores de la sociedad, como las asociaciones obreras, la masonería, y en especial, la prensa, que se convierte en el gran instrumento de control o influencia social de la época. El proceso de industrialización, incipiente, encuentra en la llegada de la epidemia un gran obstáculo: talleres y fábricas se cierran, el cinturón sanitario impide la salida de cualquier mercancía y gran parte de la clase trabajadora enferma o muere. El daño económico será uno de los principales motivos por los que las clases dominantes se vean obligadas a participar directamente en la intervención municipal en materia de salud pública; el principal resultado será la deconstrucción del plano urbano según criterios sociosanitarios, muy relacionados con el higienismo finisecular.

Por tanto, proponemos el hecho de la epidemia de cólera como factor clave en la deconstrucción de la ciudad desde el punto de vista urbanístico, deconstrucción que implica la reconstrucción de la ciudad en busca de espacios de salud. La sociedad, como afirma Lefevbre, producirá un nuevo espacio de y para la salud, tanto desde el punto de vista público como privado (2013: 125). Esta nueva producción del espacio, materia prima de la salud ciudadana, se manifiesta en función de cuatro nuevas categorías urbanas y culturales: la distribución urbana en calidad de nueva ciudad; extinción de la ciudad rural, que se traduce en la superación de la dialéctica huertos-espacios urbanos; la necesidad de obra pública; la apertura de espacios públicos de ventilación y por último, una categoría relacionada con la cultura de la salud, la concienciación de higiene pública/privada.

He aquí que hemos de interpretar la interacción de estas cuatro categorías como una manifestación del concepto dominante de biopolítica benigna, paradigmático en el desarrollo del Estado y sus instrumentos durante toda la segunda mitad del siglo XIX, sobre todo a partir de la Ley General de Sanidad, de noviembre de 1855. Esta legislación aparece como una reglamentación avanzada para su tiempo ya que contempla la Dirección General de Sanidad por primera vez como un órgano administrativo centralizado en dicha materia y atribuye las competencias sanitarias al Ministerio de Gobernación; de esta manera el artículo 54 de la legislación dice que: "las Juntas Municipales se compondrán en los pueblos de más de mil almas del alcalde, que hará de presidente, de un profesor de medicina, otro de farmacia, otro de cirugía si lo hubiere, un veterinario y tres vecinos, desempeñando las funciones de secretario, un profesor de ciencias médicas" (Gaceta, 07-12-1855). En la práctica se convirtieron en meros órganos 
consultivos sin mucho margen de decisión y expuestos a la política imperante (Gómez Martínez 2017: 59-60).

\section{EL NUEVO URBANISMO: DECONSTRUCCIÓN Y CONSTRUCCIÓN DE UNA NUEVA CIUDAD}

Según Bayly (2010: 198), el término urbanización describe un proceso aplicado a los núcleos de más de 10.000 habitantes, que la ciudad tendrá desde principios del siglo XVII, criterio que establece para diferenciar el cambio cultural que implica el predominio de valores urbanos por encima de los rurales.

Este proceso se fundamenta en cuatro grandes cambios urbanísticos: el primero de ellos es la superación de la dualidad urbana, que hasta el siglo XVIII había significado la existencia de la vila y el raval de Sant Joan como dos entidades independientes y ajenas; el segundo se ocupa del análisis de las antiguas murallas urbanísticas, que en la ciudad suponían los huertos de palmeras (Jaén 1999: 182) y la red de acequias; en tercer lugar, la importancia de las obras públicas, entre las que hemos de destacar la reforma de pavimentación e impermeabilización de las vías; y por último, la apertura de nuevos espacios de ocio y comunicación, como el paseo de la estación y la glorieta del Dr. Campello, que reorientan la ciudad y responden a las nuevas formas de vida de la ciudadanía. En la segunda mitad del siglo XVIII la bonanza del mercado del aceite y el jabón provocan importantes inversiones en la propiedad urbana (Serrano 1995: 153-154). La ciudad crece y alcanza un desarrollo urbanístico y demográfico que no superará hasta la década de finales del siglo XIX.

A mediados del siglo XIX comienzan a aparecer las primeras leyes urbanísticas que pretenden poner orden en el paisaje que el Antiguo Régimen había dejado en la ciudad. La Real Orden de 9 de septiembre de 1853 propone la construcción de barrios obreros en lugares apartados del centro urbano, hecho que no afectará a Elche, un municipio estancado y todavía sin presencia industrial. Según Pons \& Serna (1994: 111), la nueva ciudad burguesa "pretenderá la recalificación social de cada zona", frente a la supuesta promiscuidad de siglos pasados. Pero el planteamiento de Elche en este periodo, como ciudad nueva, sugiere otros problemas, sobre todo si nos centramos en la tensión campo-ciudad, que tan imbricados se encuentran en el caso de Elche debido a ese dilatado espacio de transición que significa el cinturón de huertos de palmeras fundido con el espacio urbano hasta bien avanzado el siglo XX. Esta circunstancia nos hace pensar que estamos ante una ciudad eco-urbana. 
Las antiguas murallas de Elche habían sido eliminadas entre 1838 y 1841, aunque quedarán algunos restos que irán desapareciendo durante los años siguientes, de modo que, en la década de los ochenta, son ya muy escasas las referencias a estas barreras arquitectónicas; todavía en 1901 encontramos una referencia aislada de un fragmento de muralla que ocupaba la casa recreativa del Nuevo casino de Elche (Sig. 12-2-22). No obstante, como hemos dicho, la ciudad habrá de superar otras murallas que dificultan, en la mentalidad del momento, la construcción de una ciudad industrial.

Por primera vez, el espacio urbano, la ciudad en sí misma, se convierte en un nuevo negocio, el inmobiliario, en donde la materia prima corresponde al suelo mientras podemos identificar el edificio con el producto acabado (Pons \& Serna 1994: 107). A diferentes velocidades, según sea la presión demográfica, una nueva materia prima, el espacio, elevará sus precios y modificará la rentabilidad del nuevo sector, que será uno de los más rentables por su naturaleza especulativa, tan esencial en el espíritu del capitalismo.

\section{LA EXTINCIÓN PARCIAL DE LA CIUDAD RURAL O CIUDAD DUAL}

La primera de estas murallas será la superación de la ruptura urbanística entre la vila murada y el raval de Sant Joan, antigua morería, que había perdido su jurisdicción independiente del Ayuntamiento en 1835 (Gozálvez 1976: 42). Por tanto, desde el punto de vista administrativo, a partir del primer tercio del siglo XIX ya no se puede hablar de una ciudad dual, al menos desde esa óptica formal y administrativa. Sin embargo, la vila, compuesta por las parroquias de El Salvador y Santa María, seguirá manteniendo una profunda diferencia de carácter social con respecto a los arrabales de San Juan y Santa Teresa.

Desde que la industrialización se convierte en el principal modo de vida, las fábricas y talleres emplean a más de la mitad de la mano de obra, y la ciudad es receptora de la primera fase de inmigración procedente de su propio espacio rural, dicha división social se hará cada vez más insalvable. Como ya hemos reiterado, el raval de Sant Joan es ya un barrio proletario en la segunda mitad de los ochenta, en el que la única lengua será el valenciano y la producción de suelas de alpargatas ocupará sus calles, de modo que dicho barrio se trasformará en un gran espacio de producción, características que también se desarrollan en el barrio de Santa Teresa; este sentido de localidad no será un mero punto geográfico sino una "localización física de la interacción" según Giddens (Cucó 2008: 62). Mientras, en la vila, se concentra la burguesía compuesta por las nuevas clases medias, los propietarios y el fabricants, junto a la burocracia 
municipal (Gómez Martínez 2018: 104), que, aunque también habla valenciano, conserva un compromiso al menos de carácter formal con el castellano como lengua oficial, lengua política y administrativa y lengua de cultura (Cucó 2008: 93).

Si durante el Antiguo Régimen y hasta 1609, el raval había sido la morería y después una especie de unidad administrativa independiente del municipio al modo de las antiguas universidades en otras ciudades, con su propio alcalde, a partir de mediados de la década de los ochenta del siglo XIX, la brecha entre ambas realidades, vila/raval, la proporciona el factor de clase, que más que superar la antigua dualidad vila/raval lo que hace es renovarla y actualizarla desde otros criterios.

\section{LA SUPERACIÓN DE LAS ANTIGUAS MURALLAS URBANÍSTICAS: ACEQUIAS Y HUERTOS DE PALMERAS}

Si en Valencia, como en otras muchas ciudades de la península y Europa, el derribo de la muralla es el hecho que marca la superación de una de las fronteras con una nueva época, en Elche, como ya hemos dicho, derribada durante la primera mitad del siglo XIX, quince o veinte años antes que en la capital del Turia, serán los huertos de palmeras y la red de acueductos de trazado urbano el obstáculo que el municipio tenga que salvar. Por otra parte, hemos de tener en cuenta el factor higienista - del que nos ocuparemos-, la marginación de los cementerios, que en Elche ya había tenido lugar en 1811 y el trazado de un plano más racional, de calles rectas y más anchas.

La institución del regadío es uno de los elementos económicos más importantes de la ciudad. Debido a la naturaleza agraria de la ciudad, en cuyo espacio se confunde el paisaje urbano con el de los huertos, la red de acueductos se encuentra presente casi por todas parte del plano de Elche.

El principal acueducto del que parte la mayoría de dicha red es la Acequia Mayor, que discurre longitudinalmente y por la margen más urbana del río, de norte a sur. Este acueducto será en el que se centrarán las primeras reformas, sobre todo la de 1885 , debido a las filtraciones y perjuicios que suele ocasionar en las viviendas colindantes o cercanas (El Talismán, 7: 16-04-1885), obras que todavía en 1896, continúan como uno de los principales objetivos de la Junta de Aguas y la Comisión de Ornato del Ayuntamiento (Sig. H-173-20). En 1887, la corporación municipal hace referencia a la necesidad de reformas que tienen las acequias urbanas, sobre todo en cuento a su cubrición ( $L A M, 25-08-1887)$. En 
este sentido, en 1890, el Ayuntamiento ordena las obras en la acequia que pasa por la Calle de Nuestra Señora de la Asunción, una de las más céntricas de la ciudad ( $L A M, 25-09-1890$ ). Todavía en 1900 encontramos referencias a la constante política de reformas en la red de acequias urbanas (Sig. AA-63-16) que paulatinamente será cubierta completamente durante la primera década del siglo XX.

El espacio urbano ilicitano se encuentra rodeado por un importante cinturón de huertos de palmeras, que por una parte explica la importancia de dualidad económica agrícola e industrial, y por otra, constituye un paisaje muy singular, que pronto será el principal argumento en reivindicación paisajística de una identidad local; definido este como "realidad física, engendrada por el diálogo secular entre el entorno natural y la actividad humana, tal como es percibido por la colectividad y los individuos que la integran" (Nogué 2009: 181).

Durante el siglo XIX, la política económica de desamortizaciones ha sido uno de los factores que influyen en la urbanización de los huertos ${ }^{1}$, aunque no será hasta que la presión demográfica lo demande, a partir de la década de los años noventa, cuando realmente comience un periodo de auténtica depredación de los huertos tradicionales, que no dejará indiferente a intelectuales como Pedro Ibarra, el primero en defender la importancia del paisaje como registro identitario y patrimonial de la cultura ilicitana.

Tras la urbanización de los huertos de la Puça y de Piñol, ocupados por los futuros barrios del Carmen y San Miguel, respectivamente, en 1890 y 1892, el proceso de urbanización de huertos continúa. En 1895 es subastado parte del huerto Real y del Tío Martín por Baltasar Molla Marco el 3 de febrero de 1895 (Sig. 55-24). Hacia 1900, se intensifica la expansión de la ciudad, el huerto de las patadas (en la carretera de Alicante) es urbanizado. Ese mismo año, el huerto de Gil (cerca del Ayuntamiento) es también dividido en "espaciosos solares para la construcción de casas que comprenderán de fondo todo lo que es el huerto" ( $E I$ pueblo de Elche, 74: 22-06-1900). Lo mismo ocurre con gran parte de los

\footnotetext{
${ }^{1}$ No obstante, la principal masa de huertos seguirá perteneciendo al Vínculo de la Virgen, administrado por el Ayuntamiento desde mediados del siglo tras evitar la desamortización en una sabia maniobra política del municipio que determinará la orientación del crecimiento de la ciudad y la conservación, todavía hoy, de un gran conjunto de huertos tradicionales convertidos en Parque Municipal desde mediados del siglo XX. No obstante las dificultades económicas a las que tiene que hacer frente el Ayuntamiento durante la década de los noventa lo obligarán a subastar algunos huertos, como será el caso del Real y del Tío Martín (Sig. 55-22)
} 
huertos de la zona de la Puerta de Alicante, que en 1902 son convertidos en "solares o sitios para edificar" (El pueblo de Elche, 162: 22-03-1902).

De modo que la presión demográfica que sufre la ciudad entre 1887 y 1910, que pasa de una población urbana estimada en unos 10.000 habitantes a más de 16.000, (Miranda 1991: 19) y la necesidad de solares para construir nuevas fábricas, tal es el caso de los complejos industriales de los Ferrández, Sansano Fenoll o Ripoll, producen una revolución en el paisaje que hemos de interpretar como el de unos primeros fundamentos en la construcción de la ciudad industrial.

\section{LAS OBRAS PÚBLICAS: LOS NUEVOS EDIFICIOS DE LA CIUDAD}

Tres grandes tendencias definirán la importancia de las obras públicas locales. Primero, la construcción de nuevos edificios públicos como el mercado, al que se asocia la construcción de un lavadero, el de la Troneta, de la Junta de Aguas, el matadero y el nuevo casino, a los que podríamos añadir las importantes reformas que sufre el cementerio y dos de las iglesias más importantes de la ciudad, la del Salvador y la basílica de Santa María. Segundo, el gran proyecto higienista de pavimentación y drenaje de la vía pública. Y en tercer lugar, el proceso de normalización legal que implanta el Ayuntamiento con el objeto de crear un plano mucho más racional de calles y plazas alineadas y en condiciones de seguridad e higiene adecuadas a una ciudad de progreso.

Tras la epidemia de cólera, el principal objetivo del Ayuntamiento será la construcción de un nuevo mercado que conllevará una profunda reestructuración urbanística de todo su entorno, en un proyecto "que visto el estado de adelantos del siglo y que todos los Ayuntamientos de España procuran hacer mejoras en sus respectivas poblaciones y conceptuando que una de ellas por lo que toca a esta Ciudad era la construcción de una plaza de mercado, por unanimidad se decide construir una plaza nueva, y un lavadero público" ( $L A M$, 18-11-1886).

En septiembre de 1887 se abre el "expediente para el permiso del nuevo mercado de abastos" bajo la dirección del arquitecto Manuel Chapuli, cuyas obras salen a subasta en $36.189,47$ pesetas, cuyo presupuesto ascenderá a 93.340 pesetas en agosto de 1888 ( $L A M, 05-08-1888$ ), debido al deficiente estado de cuentas municipales (Sig. 21-05). En abril de 1888, ya próximo a su inauguración, el Ayuntamiento contrata una póliza de seguros por un valor de 60.000 pesetas con La Unión Comercial para un periodo de 10 años (Sig. 34-68). Simultáneamente a 
la construcción del nuevo mercado, tiene lugar la reestructuración de su entorno, sobre todo en materia de pavimentación y alcantarillado.

El otro gran edificio es el de la Troneta, que albergará la Junta General de Aguas también en 1886. En 1903, tras varias reformas, el Ayuntamiento se decide a construir un nuevo matadero, que había sufrido una importante reforma en 1893 (Sig. 1-54), para lo que pide consejo al arquitecto Marceliano Coquillat (LAM, 21-11-1903).

En mayo 1891 finalizan las obras del lavadero, que se sitúa junto al nuevo mercado, entre las calles Alvado y del Reloj, proyecto que firma el citado maestro de obras municipal Pedro León Navarro (AA-46-23).

Durante el periodo, proliferarán las reformas en edificios públicos. En 1888, el consistorio se ve obligado a recomponer la baranda del puente de la Virgen "debido al mal estado" que será de hierro dulce o fundido y que saldrá a subasta ( $L A M, 29-11-1888)$; el puente necesitará una nueva reforma en 1901 que consistirá en la reparación de " 5 filas de sillares" (El pueblo de Elche, 112: 14-041901). También en 1888 tiene lugar la incoación del expediente de reforma de la iglesia del Salvador tras la demanda de varios vecinos afectados por el peligro que supone su estado ruinoso (Sig. 32-33), obras que todavía en 1896 seguirán pendientes de finalizar (Sig. 32-31). El Ayuntamiento asumirá también la reforma de los juzgados en 1889, en prueba de "amor a cuanto pueda tender a la cultura, claro engrandecimiento de nuestra querida Ciudad" (Sig. 23-56).

Pero quizá la obra de reforma más importante de la ciudad en este periodo sea la que recibe la basílica de Santa María, que se encontraba en estado ruinoso, sobre todo debido al abandono secular del edificio, y al efecto de las lluvias torrenciales que había padecido la ciudad en los últimos años. Y será la prensa local la primera en denunciar el estado deplorable en que se encuentra el templo mayor de la ciudad en octubre de 1901 (El Pueblo de Elche, 20-10-1901). Pocos meses después, ya en 1902, el obispo de Orihuela solicita, mediante un telegrama, la intervención urgente del arquitecto José Guardiola, que visita la iglesia (Sig. H-279-21). Pero Guardiola no será finalmente el encargado de dirigir las obras, ya que el párroco, José Antón y Tarí, preferirá confiar el proyecto a su amigo personal, el arquitecto Marceliano Coquillat Llofriu, que, habiendo acabado sus estudios universitarios en Barcelona se hace cargo del ambicioso proyecto, que firma el 15 de mayo de 1903 con un presupuesto de 132.818,40 pesetas y que se prolongará hasta 1907 (Sig. b-319). 


\section{PAVIMENTACIÓN Y DRENAJE DE LA VÍA PÚBLICA: UNO DE LOS PROYECTOS CENTRALES DE LA NUEVA CIUDAD}

Uno de los proyectos centrales, quizá el más importante de todos, es la pavimentación y drenaje de las vías públicas de la ciudad con el objeto de evitar el estancamiento de aguas y focos de infección. Tras la gran epidemia de 188485, como ocurre en otras ciudades del Mediterráneo, urbanismo y salud pública se encontrarán indisolublemente unidos, por ello serán tan importantes las obras destinadas a drenaje, alcantarillado e impermeabilización de los espacios que ha de transitar la ciudadanía.

Según Jaén (1999: 184), el interés por el pavimentado de las aceras ya se encuentra presente en la corporación municipal desde 1882. En 1884, el asunto del embaldosado de las calles de la ciudad es uno de los temas habituales de la prensa local que claman por "el embaldosado de las diferentes calles [...] de una de las ciudades más cultas de la provincia [...] que está a punto de llegar al apogeo de su grandeza" (El Vinalopó, 15-03-1884).

Pero serán las nefastas consecuencias del huésped del Ganges las que sensibilicen a la corporación en el asunto de las aguas estancadas y barrizales que tan habitualmente se apoderaban de las calles, ante lo cual, la Comisión de Ornato y Policía exigirá a los propios vecinos la existencia de sumideros particulares ( $L A M, 13-11-1884$ y 21-07-1887), ${ }^{2}$ lo mismo que a algunas obras de nivelación con el objeto de aprovechar las aguas de lluvia de las que se hará cargo Luis Cruz Pascual de Bonanza en beneficio de sus huertos (LAM, 14-031887). El Ayuntamiento pronto se hará cargo de promover -aunque parte de los gastos serán sufragados por los propios vecinos ${ }^{3}$ - la pavimentación de toda la ciudad, primero con el embaldosado desde la plaza Mayor, por ser esta el "punto de reunión y solar de los vecinos", (LAM, 28-05-1885) para continuar con las calles más céntricas de la vila hasta la calle Salvador. ${ }^{4}$ En 1888 se aborda la construcción de las aceras del tramo más cercano a la ciudad en la carretera del Alto de la Atalayas -hacia Murcia- y de Puente Ortices ( $L A M, 28-06-1888$ ). No obstante, durante los años ochenta y noventa (El Talismán, 11 y 18-03-1885; El

\footnotetext{
${ }^{2}$ El mantenimiento o reforma de los desagües también serán exigidos a cada vecino como ocurra en la calle Santa Isabel con motivo de la reforma del nuevo mercado.

3 "La colocación de aceras -según acuerdo del ayuntamiento- será de cuenta de los propietarios de casas en una latitud de tres pies, y donde fuesen más anchas, irá el esceso [sic] a cargo del Municipio" (El Vinalopó, 15-03-1884).

${ }^{4}$ Árboles, exconvento de las monjas, San Isidro, Solares, Salvador y Puerta del Arrabal. (LAM, 3-12-885).
} 
Triángulo, 29-01-1885; El Vinalopó, 28-01 y 05-04-1885; El Látigo, 07-11-1886; El Labrador, 19-05-1889; El Eco Liberal, 06-09 y 20-12-1891; El Pueblo de Elche, 19-01-1899 y 15-02-1903), no cesarán las críticas contra el estado de las aceras y las calles, que la prensa califica de barrizales, barrancs, (El Bou, 14-03 y 04-04-1885) o cenagales, "que ponen en riesgo nada menos que la salud de todo el vecindario; la salud que con tal diferencia se guarda sin que haya servido de ejemplar escarmiento los aciagos que atravesamos durante la epidemia de cólera" (El Talismán, 11-04-1885). Además de la pavimentación o enlosado, también se utilizará el engravado de muchas vías como técnica de drenaje ( $L A M, 15-02-$ 1888), como será el caso de varios tramos de la carretera del Alto de las Atalayas ( $L A M, 19-07-1888)$. Pero el gran proyecto de reestructuración es el que tiene lugar tras la construcción del nuevo edificio del mercado de abastos en pleno centro de la ciudad. En primer lugar serán empedradas las calles adyacentes a dicha plaza del mercado, es decir, San Jaime, Ereta Alta, Alvado, de la Victoria, Travesía, y Calle Mayor, así como se exige a los propietarios de la Corredora costeen las aceras de esta calle principal ( $L A M$, 05-07-1888), para cuya supervisión se nombra una comisión compuesta por Manuel Peral Fuentes, Jaime Brotons Pastor y José Pérez Sánchez (LAM, 13-09-1888).

También se construirán nuevas alcantarillas, sobre todo en la calle Victoria adyacente al nuevo mercado- por tener una pronunciada pendiente que suele inundar parte de la citada Corredora (Sig. 7-81). En definitiva, en septiembre de 1888 se encuentra ya firmado el "Proyecto de afirmado de las calles que parten de la plaza de abastos de Elche" que asciende a 5.413,20 pesetas, rubricado por Pedro León, que apelará al "orden e higiene y al grado de cultura" de la ciudad (Sig. 21-6), obras que serán subastadas en 1889 y rematadas finalmente a favor de Andrés Gomis Alonso por la cantidad de 5.398 pesetas (Sig. 21-8). Los doctores Gadea y Fernández Grau, ya denuncian en 1894, en la Junta Provincial de Sanidad, las condiciones generales de la población en cuanto a falta de alcantarillado, conducción de aguas y obras de drenaje (Gómez Martínez, 2018: 147).

Otra zona que también se embaldosará simultáneamente será la calle del cuartel de la Guardia Civil, en San Juan ( $L A M, 19-10-1901)$. Aunque la ciudad seguirá teniendo importante deficiencias de pavimentación hasta bien entrado el siglo $\mathrm{XX}$, como lo demuestran constantes alusiones a barrizales todavía en 1898 ( $L A M, 24-02-1898)$ o colocación de aceras en 1901 (LAM, 19-10-1901), la ciudad ha logrado transformar su fisonomía radicalmente en nuestro periodo estudiado. 
Las fuentes públicas serán otro motivo de importantes reformas, sobre todo debido a la iniciativa ciudadana que denuncia la insalubridad de algunas de ellas, reparadas una y otra vez a fin de evitar filtraciones o encharcamientos de agua y cuyos alrededores son pavimentados, como ocurra con la de la plaza de Santa Teresa en 1890 (Sig. 7-8) y la de la plaza de la fruta en 1891, poco después de la reforma de la plaza del nuevo mercado en 1891 (Sig. 7-25), la de la plaza de las Barcas en 1893 (Sig. 7-37), o en la de la Fonteta en el raval de Sant Joan en 1902 (Sig. 7-54).

\section{NORMALIZACIÓN MUNICIPAL URBANÍSTICA}

Por otra parte, como tercer factor de desarrollo del nuevo urbanismo nos encontramos con el proceso de normalización municipal, que consiste en el control que el Ayuntamiento mantiene sobre el trazado de las calles, su nomenclatura y rotulación, a lo que hay que sumar la ejecución de derribo de edificios en caso de peligro para el vecindario (Sig. 2-32) y permisos de edificación, que se convierten en una nueva fuente de ingresos municipales.

Desde al menos 1878 tenemos indicios de la intervención cada vez más directa del Ayuntamiento en el trazado urbanístico de la ciudad, ya que se fija un ancho mínimo de las calles de 4,5 metros (Gozálvez 1976: 93). En 1884, el Ayuntamiento delega todas las funciones y supervisiones urbanísticas en una comisión permanente que denomina de Ornato y Policía urbana, compuesta normalmente por cuatro concejales. También existe un maestro de obras municipal que nombra la propia corporación y se encarga de los aspectos técnicos. En 1889 encontramos en el cargo a Pedro León Navarro, que, como ya hemos advertido, será decisivo en la construcción del nuevo urbanismo, siendo nombrado maestro de obras municipal por la influencia del concejal y periodista José Pérez Sánchez (LAM, 04-01-1889).

Por primera vez, el permiso de obras, que habrá de ir acompañado de los convenientes planos del edificio, se convierte en un requisito imprescindible para construir o reformar una casa en el municipio, medida que afectará en especial a edificios destinados a celebrar espectáculo, como los teatros, en los que el maestro de obras realizará una conveniente inspección con el fin de que se cumplan condiciones de salubridad y seguridad, como ocurra con el teatro Vital Aza inaugurado en 1895 (Sig. 11-5-11). Así lo comunica la prensa local en febrero de 1886 (E1 Vinalopó, 06-02), y gracias al cumplimiento de esta ordenanza, podemos conocer el plano de algunas casas importantes, como la que 
proyectara Luis Cruz Pascual de Bonanza en la plaza de la Merced en 1886 (Sig. H-286-60).

En 1885 encontramos la primera referencia a la aplicación de la normativa de alineación de las fachadas en cuanto a los límites de rejas y caños (Sig. H-180-6) y una primera intervención del maestro de obras municipal sobre la línea de las casas de la calle Árboles en 1893 (Sig. 1-55), pero sobre todo será la composición del plano de la glorieta del Dr. Campello, el caso más llamativo de iniciativa vecinal que solicita permiso para reformar "las fachadas de sus respectivas casas saliendo a la línea recta que resulte de una a otra esquina de toda la acera. Esto sería una mejora de positivos resultados para todos y más principalmente a favor de la digna corporación que VS preside porque denotaría un progreso en el ornato de esta población y en el sitio más público y concurrido de la misma...", en la "propuesta de alineación de casa en plaza del Dr. Campello" (Sig. 11-6-29).

Por otra parte, a partir de la década de los noventa, el Ayuntamiento se ocupará minuciosamente del nombre y rotulación de las calles. Serán muchas las sesiones plenarias en que se decida el cambio de nombre o la rotulación adecuada de una vía o una plaza ( $L A M, 02-07-1891)$. De modo que la nomenclatura de los espacios urbanos se convertirá en una forma de reivindicar la cultura y la identidad local, ya que, por primera vez aparecerán nombres de ilicitanos ilustres que prestarán sus nombres a plazas tan importantes como la que deja el antiguo convento de las monjas, que en 1893 la corporación decide dedicar al doctor Manuel Campello Antón, lo mismo que ocurra con el Abad Pons, que será homenajeado con una calle poco después de su muerte, o el Obispo Tormo (El Pueblo de Elche, 02-06-1901), así como también haga lo propio con otros hitos de la cultura valenciana como Luis Vives, o de la política nacional como Cánovas del Castillo o Alfonso XII (LAM, 09-10-1897), o Castelar y Sagasta ( $E I$ Pueblo de Elche, 02-06-1901).

\section{LOS NUEVOS ESPACIOS ABIERTOS: OCIO, COMERCIO Y COMUNICACIÓN}

Una de las categorías de la ciudad industrial será la apertura de nuevos espacios abiertos que tengan como función el ocio, el comercio y la comunicación entre los vecinos. Ya hemos visto la importancia que adquiere la vía pública como campo de reivindicación, ahora se trata de analizar las plazas y los paseos de la ciudad como factores de cambio social.

La llegada del ferrocarril y la ubicación de la estación en la zona norte, algo lejana del casco urbano, y sobre todo separada por un cinturón de huertos de 
palmeras pertenecientes al Vínculo del Dr. Caro, hacen que el notario José Gómez Aznar proponga la apertura de la ciudad hacia la estación mediante un gran paseo que la conecte con el ferrocarril. La construcción del paseo de la estación modificará la orientación del plano de gran parte de la ciudad. Si hasta 1884, el centro neurálgico de Elche era la plaza Mayor debido a la presencia del Ayuntamiento, o la calle del Salvador como espacio comercial permanente, la apertura de la ciudad hacia la estación producirá una reorientación urbana cuyo primer resultado es la reestructuración del paseo de Bru, la plaza de la Merced e incluso, la futura glorieta del Dr. Campello.

\section{EL PASEO DE LA ESTACIÓN}

Tres meses antes de la inauguración del ferrocarril, José Gómez y Francisco Agulló, destacados miembros de la oligarquía política y económica de la ciudad proponen ante la corporación municipal que se abra "una vía recta entre la población y la estación de ferrocarril" ( $L A M, 20-03-1884)$. No exento de intereses en la zona -Gómez es propietario de varios terrenos que saldrán beneficiados en el trazado del paseo de la estación y tendrá que ceder parte del terreno en el que tiene una almazara para el ensanche del mismo (El Vinalopó, 24-08-1884) - el notario, reunido en su despacho con un nutrido grupo en el que encontramos a los hombres más influyentes de la ciudad, redacta un extenso documento en el que argumenta las innumerables ventajas de un espacio

“...tan extraordinario como pintoresco y sorprendente; allí tenemos pues la vía y la estación con todas sus dependencias, que en unos días no lejanos, por fortuna, se han de poner en explotación; pero tan cerca como está este ambicionado momento, todavía nos encontramos sin poder acercarnos a la estación a sus muelles y demás oficinas, como no sea invadiendo terrenos ajenos, puesto que aquellos edificios están enclavados en los que para el efecto fueron adquiridos por la empresa constructora... [...] esto se hace tan necesario y urgente, como que mañana mismo nos hemos de encontrar en un verdadero conflicto al hacerse imposible el transporte de las materias para la importación y exportación, como del producto de las industrias del cáñamo, elemento importante de riqueza del país, de los frutos, de dátiles, higos, granadas, y cereales de no menos importancia y sobre todo la comodidad de los viajeros" (Sig. 9-5-11). 
El escrito será convincente, y sólo siete días más tarde de su lectura en el salón de plenos, se inician las obras, que primero consistirán en la tala de 98 palmeras el 27 de marzo de 1884 (Sig. 9-5-15), previo acuerdo con el administrador del Vínculo, al que pertenecían los terrenos.

$\mathrm{Al}$ margen de la estrategia caciquil, y de los intereses que podían mover a varios de los nombres que apoyaron el proyecto de Gómez Aznar, como fuera el caso del propio marqués del Bosch o José Pomares Álamo entre otros, el proyecto del paseo de la estación significará que la ciudad industrial se acaba de poner en marcha. No obstante, las obras serán lentas, debido sobre todo, a la falta de presupuesto, por lo que incluso se llegan a plantear hasta colectas populares, como la de 1886 (EI Vinalopó, 14-03), y donaciones particulares como la del presidente de la Comisión de Ornato, Manuel Peral, que regalará las palmeras (El Látigo, 02-11-1886). En 1888, se comienzan a plantar los olmos, así como otras plantas de jardín ( $L A M, 12-01-1888$ ), aunque el Ayuntamiento todavía no ha presentado un proyecto arquitectónico del paseo, como había hecho con el nuevo mercado o incluso el paseo de Bru. Hasta 1891 no salen a subasta las obras del paseo ( $L A M, 11-04-1891)$, pero la falta de presupuesto mantiene paralizado cualquier avance, hasta 1900 cuando se terminen parcialmente las obras y el paseo quede a falta de completar su iluminación (El Pueblo de Elche, 30-091900). En abril de 1902, la corporación presenta por fin el proyecto definitivo que ha diseñado el arquitecto alicantino José Guardiola y quedará prácticamente terminado (LAM, 05-04-1902).

\section{EL PASEO DE BRU}

Arrastrado por la nueva orientación y reestructuración que provoca la ubicación de la estación de ferrocarril, el viejo paseo de Bru tendrá que ser reformado a pesar de la resistencia que opongan sus vecinos. En marzo de 1885, El Bou prestará sus páginas a las primeras críticas (14-03-1885), críticas más intensas cuando el Ayuntamiento decide su demolición, en marzo de 1885 (El Talismán, 11-03-1885), debido a su prescindibilidad al haber construido ya el Paseo de Princesa de Asturias, y estar proyectado el de la estación, además de por razones de reestructuración urbanística que tienen el objeto de conectar el citado paseo de la estación con la plaza de la merced (Sig. 32-45). La decisión provocará muchas críticas que habrán de prolongarse durante toda la década, sobre todo lideradas por Luis Cruz Pascual de Bonanza, cuyo argumento se centrará en la ventilación y ensanche que proporciona al barrio y en el daño que su demolición provocaría en los intereses de muchos de sus vecinos (El Bou, 13-12- 
1885; Los Obreros, 19-09-1886), que incluso promoverán una suscripción popular en 1886 ( $E 1$ Vinalopó, 07-03), quejas que se prolongarán hasta los primeros años del siglo XX (El Pueblo de Elche, 03-11-1901).

Unida a la reestructuración que sufre el paseo de Bru, encontramos la reforma de la plaza de la Merced, donde es instalada una fuente ornamental que acompañará a la nueva fuente de agua potable ( $L A M, 06-10-1887)$, inaugurada con banda de música, cohetes, fuegos artificiales y volteo de campanas en diciembre de 1887 (La Libertad, 18-12-1887).

\section{LA GLORIETA DEL DR. CAMPELLO}

Si la estación del ferrocarril supone un nuevo polo al que se orienta la nueva ciudad, como consecuencia de esta nueva orientación, surge la glorieta del Dr. Campello en el solar que deja la demolición del ruinoso convento de las monjas, derribado definitivamente en 1891. La nueva plaza será muy importante porque constituirá un eje comercial y de comunicación que jalone la ciudad desde la plaza Mayor, la Corredora y la citada glorieta.

En abril de 1885, el efecto de las lluvias torrenciales ha causado severos daños a un ya ruinoso convento que ocupa el centro de la ciudad (El Talismán, 11-031885 ) en cuyo claustro se solían celebrar espectáculos taurinos y circenses. El Alcalde y varios de sus concejales, acompañados de Manuel Campello, se presentan en el citado convento de Santa Clara con el fin de observar los daños (El Talismán, 16-04-1885). La corporación decidirá el derribo del edificio, que ya desde 1873, había sido considerado un peligro para la población a causa del estado en que se encontraba (El Pueblo de Elche, 31-05-1891). En 1891, en el solar que ha dejado el convento, se proyecta la construcción de una gran glorieta pública que, por iniciativa ciudadana dirigida por José Rodríguez, Joaquín Santo y Luis Llorente, habrá de llamarse del Dr. Campello (Sig. 11-1-30). No obstante, la demora de las obras permite que en dicho espacio se celebre la feria de San Andrés en 1891 (El Eco Liberal, 26-11-1891), aunque una instancia de vecinos y comerciantes solicitará del Ayuntamiento que la feria regrese a la plaza Mayor al año siguiente (Sig. 33-55). La prensa local se convertirá en uno de los sectores de la opinión pública más decididos en la defensa de la creación de la glorieta, que asocia "con el progreso de su querida ciudad". Los principales garantes de la apertura de dicha plaza serán José Gómez Aznar y Manuel Campello (El Pueblo de Elche, 31-05-1891). Pero la lentitud de la burocracia y la falta de presupuesto retrasan el proyecto de una plaza que el Ayuntamiento pretende convertir en el nuevo centro neurálgico de la ciudad, como así será hasta incluso entrado ya el 
siglo XXI. A principios de 1896, el pleno municipal presidido por el alcalde Jaime Brotons, encarga al ingeniero agrónomo Mariano Llofriu el diseño de la nueva plaza ( $L A M, 04-01-1896)$, que plantea una plaza-jardín rodeada de árboles con un parterre o columna de hierro ( $L A M, 05-04-1902)$ en su centro, en el que se puedan celebrar conciertos de música ( $L A M, 01-02-1896)$, y que se convierte en un gran espacio de ocio social para la ciudadanía.

Además de los citados, la ciudad contará con otros paseos y plazas que también serán reformados en este periodo, como el paseo Chilindrón que debido a su "deplorable estado" ( $L A M, 21-02-1891)$, y la influencia del Paseo de la Estación, será aprobada su reforma en febrero de 1891 y rodeado por una verja metálica en mayo de ese mismo año (El Eco Liberal, 10-05-1891). También en 1891 el Ayuntamiento intenta la reparación del paseo de Calendura, que también se encuentra en muy mal estado según la inspección del maestro de obras Pedro León (Sig. 11-1-14). También se intenta normalizar el modo de exposición de los productos que los comerciantes ofertan en la calle Salvador, que llega a impedir el tránsito de los viandantes según una denuncia que llega a la Comisión de Ornato municipal en 1892 (Sig. 2-62).

\section{EL PLANTEAMIENTO ESTÉTICO DE LA NUEVA CIUDAD}

El otro factor que hemos de unir al proceso de construcción de la ciudad industrial es el factor estético que estará presente en muchas de las acciones del Ayuntamiento y su Comisión de Ornato. El fervor reformista y la inquietud que demuestran los ayuntamientos ilicitanos y la opinión pública con respecto a la apertura de nuevos espacios donde se desarrolle el ocio, el aspecto, la música o las actividades comerciales tendrá también un objetivo estético. La ciudad aparece ante la sociedad como un sujeto de belleza.

La función estética surgirá en los años ochenta como un concepto de revalorización de calles y espacios urbanos, idea derivada del progreso y la cultura de la ciudad, argumento que suele ocupar un lugar privilegiado en el discurso oficial de los políticos locales, pero también en las aportaciones de la prensa, que no sólo llamará la atención sobre las reformas municipales, sino también sobre la construcción de nuevos edificios privados que contribuirán a embellecer la ciudad, como las casas de la nueva burguesía, en el caso de Daniel Fenoll, José Bernad, el alcalde Andrés Tarí, la fachada del casino o el hotel de José Pomares Álamo (El Bou, 13-06-1885). 
Es precisamente la cuestión estética uno de los argumentos que justificarán el proceso de normalización ya que,

"dado el grado de cultura y civilización alcanzado en esta población, cuyo rápido progreso debía armonizarse con todo lo relativo a policía y embellecimiento de la misma consideraba conducente al efecto obligar a los propietarios de fincas urbanas, al enlucido de las fachadas respectivas, siempre que necesitasen solicitar licencia del Ayuntamiento para reparar, con lo cual conseguiríamos el ejemplo de otras Ciudades alcanzado en pocos años el buen aspecto de la nuestra, proposición aprobada por una unanimidad aunque precedida de breve discusión" (LAM, 25-06-1891).

Por otra parte, el trazado de las calles será uno de los factores que más habrá de influir en la nueva estética de la ciudad; todavía en 1902, uno de los concejales propone que las calles del nuevo trazado sean rectas y que las casas "que en dicho barrio se instalen sean una mejora para el ornamento y embellecimiento de la población" ( $L A M, 31-08-1902)$. El plano de la ciudad será cada vez más racional.

\section{EL CONCEPTO DE HIGIENE Y SALUD PÚBLICA: UN ASPECTO DEL NUEVO URBANISMO Y LA SOCIEDAD CIVIL}

Como ya hemos visto, uno de los principales objetivos del nuevo urbanismo será evitar los focos de infección relacionados con el agua estancada. Por primera vez se entiende la salud como un derecho ciudadano, del que será garante el propio municipio. Además la ciudad es interpretada como un organismo vivo en el sentido neohipocrático (Pinol 2011: 129), por ello es tan importante la circulación de los fluidos: el agua y el aire. Tanto las obras de pavimentación, alcantarillado y drenaje, como la preocupación de facilitar el acceso al agua potable, que se completará con la futura llegada de las aguas de la Alcoraya ${ }^{5}$ en los primeros años del siglo XX o la regulación de vertidos industriales e instalación de fábricas, son objetivos políticos propios de un progreso entendido como liberación de las epidemias y elevación del grado de bienestar ciudadano. La higiene, siguiendo la trayectoria catalana (Galiana; Bernabeu-Mestre 2006:

${ }^{5}$ Compañía de agua potable cuya sociedad firma un contrato con el Ayuntamiento de la ciudad en el mes de junio de 1899, por el que se le concede el monopolio de explotación de las aguas para el consumo humano (Gómez Martínez, 2017: 148; Frau, 2004: 92). 
151), se entiende como un derecho, pero también como una obligación de la ciudadanía, de ahí que el Ayuntamiento, institución que representa al Estado, dirija los trabajos de organización y normalización de la higiene pública, pero también se encargue de mentalizar y obligar al pueblo de sus responsabilidades sociales -ya hemos visto como en muchos bandos municipales se anima al rociado de los portales individuales-, de ahí la transversalidad del concepto salud pública, repartido entre arquitectura, urbanismo, educación, medicina y sociedad civil.

En este mismo sentido, preventivo e higiénico, hemos de situar el interés del Ayuntamiento por las condiciones de salubridad en que viven los presos de la cárcel, que sigue periódicamente un régimen de visitas semanales supervisadas por médicos de prestigio social como el Dr. Campello o Santiago Pomares Ibarra. $^{6}$

\section{LA ORGANIZACIÓN MUNICIPAL DE LA HIGIENE PÚBLICA}

Tras superar el cólera de 1884-85 con graves pérdidas humanas y económicas, dentro de la amplitud del concepto salud pública, nos encontramos con el hecho concreto de la organización de la higiene colectiva en una ciudad en expansión fabril y demográfica, en la que el Ayuntamiento mantiene y emprende una serie de medidas: el control sobre la hidrofobia y los perros, la recogida periódica de basuras y la manipulación de carnes.

El problema de los perros que andan sin amo por las calles será una preocupación municipal presente también en la prensa. En agosto de 1884 encontramos la primera referencia a una primera campaña municipal de exterminio de "perros vagabundos" (LAM, 21-08-1884). En 1893, el Ayuntamiento da lectura en el pleno municipal a un "informe de la hidrofobia" y acuerda continuar con la administración anual de "extricnina", veneno para perros ( $L A M, 04-05-1884$ y 27-08-1898). En cuanto a la organización de recogida de basuras, también será un nuevo servicio municipal derivado de la reestructuración, que supone la nueva plaza del mercado arrendada por el Ayuntamiento igual que la gestión de pesos o medidas u otras actividades. En septiembre de 1887, tenemos noticia de la instancia que presenta José Pérez Sánchez solicitando 3 pesetas diarias por el derecho de recoger las "basuras e

${ }^{6}$ El AHME cuenta con una serie documental completa de los Libros de Visita a cárceles de todo el periodo que suele encontrarse en los legajos de Correspondencia municipal, aunque todavía sin clasificar. 
inmundicias que se encuentran en esta ciudad a cuyo fin tendrá dispuesto un carruaje y dos peones" (Sig. 38-49). A la vez, el Ayuntamiento organiza el rociado de las principales vías ( $L A M$, 05-05-1887), y en 1892, la corporación debate la necesidad de una bomba de agua para regar las calles e incluso faculta al concejal e industrial Antonio Bordonado para que gestione su compra. En 1895 tenemos noticia del arrendamiento del servicio de recogida de basuras, que será concedido para 4 años por la cantidad anual de 121,25 pesetas, en el que se especifica que el servicio se hará por uno o más carros, a diario, en la plaza de abastos y, por primera vez, las casas podrán solicitar la retirada de sus residuos (Sig. 38-37). A partir de 1892, el Ayuntamiento también asume su responsabilidad de control sobre el vertido de residuos industriales, estiércol, basuras, o escombros en acequias y caminos como el de Alicante (Sig. 2-16), San Antón (Sig. 11-2-79) o el de los Molinos (Sig. 12-41), huertos como el del Bou, en el que se denuncia un depósito de basura ( $L A M, 20-06-1903)$, o el de la Puerta de la Morera (Sig. 4-38) y actúa de oficio, o alertado por las denuncias que promueven los vecinos.

Como resultado de la construcción del mercado y la reforma de la zona que supone, el arquitecto Chapuli propone la construcción de una columna mingitoria ${ }^{7}$ en la nueva plaza de abastos, en 1888. También será a principios de la década de los noventa cuando el Ayuntamiento intervenga en la regulación de la venta de alimentos en la calle. Tras el episodio de cólera de 1890, abundarán las solicitudes de autorización de la tradicional matanza (Sig. 38-66), pero los comerciantes del mercado presionarán para que se prohíba dicha costumbre, así como la venta de carne en fresco (Sig. 38-65). No obstante, la tradicional "matanza del cerdo" -o del porc- se encuentra muy arraigada en toda la cultura mediterránea y será difícil de combatir. Como viene a decir Braudel (1976:431), dicha prohibición será uno de los factores más importantes de ruptura entre la ciudad rural y la apertura a la ciudad industrial. Durante toda la década, y aún ya avanzado el siglo XX, abundarán las denuncias por cría de cerdos, "vulgarmente llamados de San Antón" ( $L A M, 03-08-1895$ y 10-10-1896), matanzas y venta de carnes en la calle (Sig. 38-55; Sig. 38-40; Sig. 41-52-6).

\footnotetext{
${ }^{7}$ LAM, 26-04-1888. En 1889 se condena el meadero público que existía en la calle Ereta tras la denuncia del vecindario, por ser "más bien que un servicio público un foco perjudicial tanto para los vecinos como para los transeúntes" (Sig. 2-15).
} 


\section{BIBLIOGRAFÍA}

BAYLY, C. (2010): El nacimiento del mundo moderno 1790-1914, Madrid, Siglo XXI.

BRAUDEL, F. (1976): El Mediterráneo y el mundo mediterráneo en la época de Felipe II, vols. I. Madrid, Fondo de Cultura Económica.

CUCÓ I GINER, J. (2008): Antropología Urbana, Barcelona, Ariel.

DARDÉ, C. (2003): Política y políticos españoles de la Restauración (1875-1900), Madrid, Biblioteca Nueva.

FRAU VICENTE, J. (2004): Elx: 1'aigua de l'Alcoraia. La Rella, Elx, 17, 83-114.

GALIANA, M.E.; BERNABEU-MESTRE, J. (2006): El problema sanitario de España: saneamiento y medio rural en los primeros decenios del siglo XX. Asclepio, Revista de Historia de la Medicina y de la Ciencia, Universidad de Alicante, 58(2), 139-164.

GÓMEZ MARTínEZ, M.R. (2017): Pobreza y Salud Pública a través de los discursos periodísticos locales. Elche (1923-1930). Tesis doctoral inédita. Universidad de Alicante, Departamento de Sociología.

GÓMEZ MARTÍNEZ, M. R. (2018): Crónica de la pobreza. Orígenes de la Asistencia Social en una ciudad del mediterráneo, Elche, 1923-1930, Elche, Cátedra Pedro Ibarra, Universidad Miguel Hernández.

GOZÁLVEZ PÉREZ, V. (1976): La ciudad de Elche. Estudio geográfico, Alicante, Facultad de Filosofía y Letras.

JAÉN I URBÁN, G. (1999): D'aigua i obres hidràuliques a Elx, Alacant, Universitat d'Alacant.

LEFEBRVE, H. (2013): La producción del espacio, Madrid, Capitán Swing.

MIRANDA ENCARNACIÓN, J. A. (1991): Hacia un modelo industrial. Elche, 1850-1930, Alicante, Instituto de Cultura Juan Gil-Albert.

MONGE JUÁREZ, M. (2018): La epidemia de cólera morbo de 1884 en Elche; un elemento de cambio de sociedad y una nueva categoría de la contemporaneidad. Cultura de los cuidados: Revista de Enfermería y Humanidades, 51, 31-37.

NOGUÉ, J. (ed.) (2009): La construcción social del paisaje, Madrid, Biblioteca Nueva. 
PINOL, J. L. (dir.) (2011): Historia de la Europa urbana. IV. La ciudad contemporánea hasta la Segunda Guerra Mundial, València, Universitat de València.

PONS, A. \& SERNA, J. (1992): La ciudad extensa. La burguesía comercialfinanciera y su dominación en la Valencia de mediados del siglo XIX, València, Diputación Provincial.

SERRANO I JAÉN, J. (1995): De patricis a burguesos. Les transformacions dùna oligarquía terratinent, ElX, 1600-1855, Alacant, Institut de Cultura "Juan Gil Albert", Diputació Provincial d'Alacant, Ajuntament d'Elx.

VV.AA. (1986): Cien años de Historia de Elche (1886-1986), Alicante, Caja de Ahorros de Alicante y Murcia.

\section{ARCHIVO HISTÓRICO MUNICIPAL DE ELCHE (AHME)}

El Bou, número 2 y 5, del 14 de marzo y 4 de abril de 1885 (PH-89. AHME)

El Bou, número 15, del 13 de junio de 1885. (PH-89. AHME)

El Bou. "Protesta por la demolición del paseo de Bru", número 40, del 13 de desembre de 1885 (PH-146. AHME)

El Eco Liberal, número 6, del 10 de mayo de 1891 (PH-9. AHME)

El Eco Liberal, número 34, del 26 de noviembre de 1891 (PH-9. AHME)

El Eco Liberal, número 23 y 37, del 6 de septiembre y 20 de diciembre de 1891(PH-9. AHME)

El Labrador. "Noticias", número 14, del 19 de mayo de 1889 (PH-89. AHME)

El Látigo. "Latigazos", número 2, del 7 de noviembre de 1886 (PH-84. AHME)

El Látigo. "Chasquidos", número 2, del 7 de noviembre de 1886 (PH-84. AHME)

El pueblo de Elche. "Plaza del Dr. Campello", número 3, del 31 de mayo de 1891 (PH-86. AHME)

El pueblo de Elche, número 3 y 173, del 19 de enero de 1899 y el 15 de febrero de 1903. (PH-13 y 14. AHME)

El pueblo de Elche, número 74, del 22 de junio de 1900 (PH-13. AHME)

El pueblo de Elche, número 84, del 30 de septiembre de 1900 (PH-13. AHME) 
El pueblo de Elche, número 112, del 14 de abril de 1901 (PH-14. AHME)

El pueblo de Elche, número 119, del 2 de junio de 1901 (PH-14. AHME)

El pueblo de Elche, número 140, del 20 de octubre de 1901 (PH-14. AHME)

El pueblo de Elche, número 142, del 3 de noviembre de 1901 (PH-14. AHME)

El pueblo de Elche, número 162, del 23 de marzo de 1902 (PH-14. AHME)

El Talismán. "Las calles de Elche", número 5, del 1 de abril de 1885 (PH-84. AHME)

El Talismán. "Ecos", número 7, del 16 de abril de 1885. (PH-84. AHME)

El Talismán, número 2 y 3, del 11 y 18 de marzo de 1885 (PH-84. AHME)

El Triángulo, número 1, del 29 de enero de 1885 (PH-84. AHME)

El Vinalopó. "Los embaldosados", número 5, del 15 de marzo de 1884 (PH-39. AHME)

El Vinalopó, número 28, 24 de agosto de 1884 (PH-39. AHME)

El Vinalopó. "Hablillas", número 52 y 62, del 28 de enero y 5 de abril de 1885 (PH-84. AHME)

El Vinalopó, número 72, del 6 de febrero de 1886 (PH-84. AHME)

El Vinalopó. "Hablillas", número 76, del 7 de marzo de 1886. (PH-84. AHME)

El Vinalopó, número 77, del 14 de marzo de 1886 (PH-84. AHME)

Gaceta de Madrid, oo 1068, de 7 de diciembre de 1855

La Libertad, número 43, del 18 de diciembre de 1887 (PH-89. AHME)

Los Obreros, número 3, del 19 de septiembre de 1886 (PH-84. AHME)

LIBRO DE ACTAS MUNICIPAL (LAM) (AHME)

$L A M$, sesión del 20 de marzo de 1884 (Sig. a 176. AHME)

$L A M$, sesión del 4 de mayo de 1884 (Sig. a 184. AHME)

$L A M$, sesión del 21 de agosto de 1884. Folio 63 (Sig. a 176. AHME)

$L A M$, sesión del 13 de noviembre de 1884. Folio 87 (Sig. a 176. AHME)

$L A M$, sesión del 28 de mayo de 1885. Folio 25 vuelto (Sig. a 177. AHME) 
SOCIOLOGÍA HiSTÓRICA (SH)

$L A M$, sesión del 3 de diciembre de 1885. Folio 59 vuelto-60 (Sig. a 177. AHME)

$L A M$, sesión del 18 de noviembre de 1886. Folio 143 (Sig. a 177. AHME)

$L A M$, sesión del 14 de marzo de 1887 (Sig. a 178. AHME)

$L A M$, sesión del 5 de mayo de 1887. Folio 96. (Sig. a 178. AHME)

$L A M$, sesión del 21 de julio de 1887. Folio 110 vuelto (Sig. a 178. AHME)

$L A M$, sesión del 25 de agosto de 1887. Folio 122 (Sig. a 178. AHME)

$L A M$, sesión del 6 de octubre de 1887. Folio 151 (Sig. a 178. AHME)

$L A M$, sesión del 12 de enero de 1888. Folio 5 (Sig. a 179. AHME)

$L A M$, sesión del 15 de febrero de 1888. Folio 16 vuelto (Sig. a 179. AHME)

$L A M$, sesión del 26 de abril de 1888. Folio 38. (Sig. a 179. AHME)

$L A M$, sesión del 28 de junio de 1888. Folio 57 vuelto (Sig. a 179. AHME)

$L A M$, sesión del 5 de julio de 1888. Folio 62 (Sig. a 179. AHME)

$L A M$, sesión del 19 de julio de 1888. Folio 65 vuelto (Sig. a 179. AHME)

$L A M$, sesión del 5 de agosto de 1888. Folio 73 (Sig. a 179. AHME)

$L A M$, sesión del 13 de septiembre de 1888. Folio 84 vuelto (Sig. a 179. AHME)

$L A M$, sesión del 25 de octubre de 1888. Folio 104 vuelto (Sig. a 179. AHME)

$L A M$, sesión del 29 de noviembre de 1888 (Sig. a 179. AHME)

$L A M$, sesión del 4 de enero de 1889. Folio 9 (Sig. a 180. AHME)

$L A M$, sesión del 25 de septiembre de 1890 (Sig. a 181. AHME)

$L A M$, sesión del 21 de febrero de 1891 (Sig. a 182. AHME)

$L A M$, sesión del 11 de abril de 1891 (Sig. a 182. AHME)

$L A M$, sesión del 25 de junio de 1891 (Sig. 182. AHME)

$L A M$, sesión del 2 de julio de 1891 (Sig. a 182. AHME)

$L A M$, sesión de 3 de agosto de 1895 (Sig. a 186. AHME)

$L A M$, sesión del 4 de enero de 1896 (Sig. a 187. AHME)

$L A M$, sesión del 1 de febrero de 1896 (Sig. a 187 y P-9-1. AHME)

$L A M$, sesión del 10 de octubre de 1896 (Sig. a 187. AHME) 
LAM, sesión del 9 de octubre de 1897 (Sig. a 188. AHME)

$L A M$, sesión del 24 de febrero de 1898. Folio 75 y 76 (Sig. a 189. AHME)

$L A M$, sesión del 27 de agosto de 1898. Folio 131 (Sig. a 189. AHME)

LAM, sesión del 19 de octubre de 1901 (Sig. a 194. AHME)

$L A M$, sesión del 5 de abril de 1902 (Sig. a 193 I. AHME)

$L A M$, sesión del 5 de abril de 1902. Folio 24 vuelto (Sig. a 195. AHME)

$L A M$, sesión del 31 de agosto de 1902. Folio 80 (Sig. a 195. AHME)

$L A M$, sesión del 20 de junio de 1903. Folio 53 (Sig. a 196. AHME)

$L A M$, sesión del 21 de noviembre de 1903. Folio 99 (Sig. a 197. AHME)

Sig. 12-2-22. AHME

Sig. H-173-20. AHME

Sig. AA-63-16. AHME

Sig. 55-22. AHME

Sig. 55-24. AHME

Sig. 21-05. AHME

Sig. 34-68. AHME

Sig. 1-54. AHME

Sig. 32-33. AHME

Sig. 32-31. AHME

Sig. 23-56. AHME

Sig. H-279-21. AHME

Sig. b-319. AHME

Sig. AA-46-23. AHME

Sig. 7-81. AHME

Sig. 21-6. AHME

Sig. 21-8. AHME 
SOCIOLOGÍA HISTÓRICA (SH)

Sig. 7-8. AHME

Sig. 7-25. AHME

Sig. 7-37. AHME

Sig. 7-54. AHME

Sig. 7-8. AHME

Sig. 7-25. AHME

Sig. 7-37. AHME

Sig. 7-54. AHME

Sig. 2-32. AHME

Sig. 11-5-11. AHME

Sig. H-286-60. AHME

Sig. H-180-6. AHME

Sig. 1-55. AHME

Sig. 11-6-29. AHME

Sig. 9-5-11. AHME

Sig. 9-5-15. AHME

Sig. 32-45. AHME

Sig. 11-1-30. AHME

Sig. 33-55. AHME

Sig. 11-1-14. AHME

Sig. 2-62. AHME

Sig. 38-49. AHME

Sig. 38-37. AHME

Sig. 2-16. AHME

Sig. 11-2-79. AHME

Sig. 12-41. AHME

Sig. 4-38. AHME 
Sig. 2-15.AHME

Sig. 38-66. AHME

Sig. 38-65. AHME

Sig. 38-55. AHME

Sig. 38-40. AHME

Sig. 41-52-6. AHME

Recibido: 8 de octubre de 2019

Aceptado: 3 de diciembre de 2019

María Rosa Gómez Martínez es Doctora en Sociología por la Universidad de Alicante, Trabajadora Social por la Universidad de Alicante y Máster oficial en Antropología, Cultura, Migración y Salud por la Universidad de Murcia. Es autora de varios libros y artículos sobre pobreza y salud desde la perspectiva de la Sociología histórica. mariarosa.gomez@um.es 